\title{
Propuesta educativa para ir del individualismo a la integración social comprometida
}

\author{
Educational proposal for going from individualism to the \\ social commitment integration
}

\author{
Ana Teresa López de Llergo \\ Universidad Panamericana, México \\ Correspondencia: alopezde@ \\ up.edu.mx
}

Recibido: 03-11-2015

Aceptado: 12-08-2016

\section{Resumen}

El ser humano es un sujeto persona que, desde la dimensión intrasubjetiva, se posee y se autoconduce. Desde la dimensión intersubjetiva enriquece la intrasubjetividad con las múltiples influencias de los demás y así aumenta su experiencia. Por eso, para el desarrollo, es necesaria la ayuda de los semejantes. La estructura y los enfoques del entorno contemporáneo fomentan, casi exclusivamente, la intrasubjetividad, desencadenándose un individualismo exagerado que asfixia la intersubjetividad propia de quien es consciente de la deuda recíproca entre los miembros de la sociedad. La educación en este terreno ha de lograr el acto voluntario de la colaboración sostenida. Esto incluye la apertura para asumir las consecuencias de los sucesos, la sutileza de compartir las responsabilidades y la cordialidad para abordar los sufrimientos comunes y forjar el destino. Desde la familia, estos objetivos han de cultivarse específicamente; desde la escuela, se han de ofrecer medios para hacer posible la participación en iniciativas que den cauce a la solución de algunas necesidades; y la sociedad ha de ofrecer recursos.

Palabras clave: Educación, individualismo, integración social, libertad, compromiso. 


\begin{abstract}
The human being is a person who, from the intrasubjective dimension is possessed and self-conducting. From the intersubjective dimension it enriches the intrasubjectivity with the multiple influences of the others and thus increases its experience. That is why, for development, the help of others is necessary. The structure and approaches of the contemporary environment almost exclusively promote intrasubjectivity, triggering an exaggerated individualism that suffocates the intersubjectivity of the ones that are aware of the reciprocal debt among the members of society. Education in this field has to achieve the voluntary act of sustained collaboration. This includes the opening to bear the consequences of the events, the subtlety of the sharing of responsibilities, and the cordiality to address the common suffering and forge fate. From the family these objectives have to be cultivated specifically; the school, must offer the possibilities to participate in initiatives where the solution to some needs can be found; and society has to offer resources.
\end{abstract} Key words: Education, individualism, social integration, liberty, commitment.

\title{
La participación comprometida
}

La responsabilidad de la participación comprometida se basa en que toda acción, realizada en lo oculto o en público, individual o grupalmente, tiene repercusiones imputables. Como veremos a continuación, la participación es una tendencia natural, todos la tenemos, aunque desgraciadamente no siempre está bien encauzada, debido a malas influencias. Para la participación comprometida se requiere la voluntad de involucrarse y, en este aspecto, ya es necesario otro nivel en la formación de la libertad:

Y si, en efecto, el hombre fuese naturalmente un animal solitario, le bastarían las pasiones del alma, con las cuales se acomodaría a las cosas, para tener en sí un conocimiento de ellas; pero como el hombre es por naturaleza un animal político y social, fue necesario que los conocimientos de un hombre se manifestasen a otros, lo que se hace por la voz; y por ello fue necesario que hubiese voces significativas, en orden a que los hombres conviviesen entre sí (Tomás de Aquino, Suma Teológica, I, q. 13, a. 1, c.).

Este texto expone una realidad de la cual todos somos testigos. En la vida cotidiana contamos con evidencias y, si reflexionamos, somos capaces de sacar conclusiones indudables. En este caso, podemos afirmar que detrás de la voz hay algo más: una facultad que recoge conocimientos, que se da cuenta de ellos y que necesita compartirlos, se trata de la inteligencia. Además, el hecho de compartir nos descubre la necesidad de entablar relaciones con semejantes que capten y entiendan lo que les queremos decir, para lograr esto, es necesario inventar un cauce común, se trata 
del lenguaje. Y así, vamos entendiendo el entramado de la riqueza encerrada en el ser humano y cómo los beneficios se vuelven exponenciales cuando todos aportamos. Captamos, comunicamos, inventamos y perfeccionamos al asumir y aplicar las ideas propias y las de los demás, esto es enriquecer el bien común:

El bien común tiene su propio sentido, que no es solamente la suma de los bienes individuales. Es más: en el bien común se hace patente de manera más inmediata que en la sociedad el hecho de que lo social sea una entidad supraindividual, aun cuando no posea un ser independiente del de los individuos. Dicha entidad consiste en el acercamiento de la prestación común resultante de la recíproca vinculación de las prestaciones individuales. El ordenamiento jurídico, por ejemplo, es fundamental patrimonio de la sociedad, no es imaginable sin la existencia de la comunidad; es imposible que cada uno por sí vele por sus derechos. [...] [El bien común] es una totalidad a la cual se ordena el bien individual de los miembros de la sociedad como la parte al todo (Messner, 1976, p. 355).

La tendencia a la superación, al perfeccionamiento puede encontrarse en las obras que producen las personas. Los aparatos sirven para facilitar y mejorar lo que hacemos; y, entre los diversos productos, están las obras de arte, donde se expresan variados aspectos de la intimidad y, sobre todo, se enmarcan en el campo de lo bello. En este terreno se llega a manifestaciones que tal vez no lograríamos con otros recursos.

Rufino Tamayo (1899-1991), reconocido pintor y muralista mexicano, no hizo gala de religiosidad, sus planteamientos giraban en torno a la persona y a la importancia de comprometerse con el presente. Tiene una pintura cubista en el Museo de Bellas Artes en Dallas, Texas. Se titula Hombre. En colores ocres, en el plano inferior, representa a un hombre arrodillado con las piernas abiertas, la izquierda, adelantada, y ambas, sólidamente apoyadas sobre la tierra, los dedos de los pies se sumergen en el barro. Está de espaldas, muy cerca de su pierna izquierda se agazapa un animal. La solidez de la base contrasta con el vigor con que se yergue la espalda, y el brazo derecho permanece alzado hacia un cielo plagado de estrellas con un acento de luz en el recorrido circular de un pequeño cometa. El mensaje es muy claro: el hombre que pisa la tierra y la comparte con los animales se alza al infinito, su rostro mira hacia la inmensidad. Es el mensaje de la trascendencia, el ser humano busca las alturas, y muchos, aunque no lo sepan o lo nieguen, anhelan a Dios.

Estos ejemplos de la expresividad humana, por diversos caminos, afirman la participación; sin embargo, todavía falta el compromiso, el ejercicio de la libertad que asume la colaboración y además la sostiene, aunque aparezcan dificultades. 
El actuar en libertad incluye la elección, y la elección se da en una disyuntiva entre dos bienes, entre el bien y el mal, o entre dos males. Este es el campo de la moral, ligado con la verdad, que nos hace descubrir el auténtico bien, porque siempre que se hace una elección se busca el bien, pero cuando se elige el mal es por alejarse de la verdad culpablemente o no. En el tema del conocimiento de la verdad abundaremos en el tercer apartado.

El ejercicio de la libertad requiere de la madurez de decidir por lo mejor entre múltiples posibilidades, y no es desarraigo, sino compromiso. La libertad está vinculada al amor y al bien; el amor crea lazos, el bien eleva y dispone los siguientes pasos a la superación (González Simancas, 1992, p. 120).

Hemos de volver a los principios para conseguir aclarar la dimensión moral. El siguiente argumento da luz en este aspecto:

Sería un error desastroso incluso en la naturaleza de la cosa la constitución moral de la sociedad en «cuanto tal». De este modo podría llegarse a este razonamiento: En nuestra sociedad la mayoría de los miembros son caníbales, cosa que no se puede cambiar, por tanto, el que se devoren unos a otros forma parte de la naturaleza de la cosa y consiguientemente del derecho natural [...]. El derecho natural es no sólo ley jurídica, sino en primer lugar ley moral, es decir, bajo un primer aspecto es imperativo natural de perfeccionamiento moral del hombre en su naturaleza individual y social. Pero en cuanto expresa a la vez normas de la vida en común, tiene carácter jurídico. El lado individual y el social de la ley natural son como dos funciones de una misma ley (Utz, 1965, p. 113-114).

\section{Circunstancias contemporáneas}

Todo cambio incluye una crisis, y la historia del ser humano está trenzada con el cambio. Cada cambio tiene su propio perfil, a veces muy agresivo y con planteamientos de ruptura respecto a la tradición, otras veces resulta más tranquilo, y de manera ponderada adopta nuevas formas, pero también incluye las del pasado. Actualmente, los planteamientos son drásticos y tienden a no reconocer los antecedentes. Por eso, parece que las instituciones han perdido sus cimientos. En estas circunstancias es evidentemente grave la crisis actual de la familia. Se manifiesta sobre todo en el frecuente rechazo de los valores tradicionales como la fidelidad conyugal y la misión educadora de los padres. Estos problemas provienen, a su vez, de una crisis de civilización que tiende a ver los sucesos como el resultado de una evolución sociocultural inexorable. Además, la aldea global de Marshall McLuhan, paradójicamente, en lo social, desencadena una reacción contraria: los localismos; y, en las relaciones humanas, la facilidad de la interconexión también presenta otro contraste: el ensimismamiento con las consecuencias del aislamiento y distanciamiento del prójimo, sea miembro de la familia, compañero de trabajo, vecino, etcétera (McLuhan \& Powers, 2007). 
Algunos factores sociales modifican radicalmente su significado, ya que los adelantos tecnológicos aplicados a la ciencia han provocado una revolución sin precedentes. Específicamente, el tema de la demografía afecta profundamente el modo tradicional de concebir el matrimonio y la familia, debido a la adopción del control natal, del aborto, de la eutanasia, del divorcio. Así, se altera la sociedad en aspectos coyunturales como es el moral, el legislativo, el económico. Los efectos prácticos saltan a la vista: (1) La precariedad de la fidelidad conyugal. (2) La modificación de la actividad de la mujer, sobre todo en el terreno laboral, con sus efectos en la vida matrimonial y familiar. (3) La duración de la vida, centrada principalmente en el bienestar físico con el menosprecio de los valores espirituales. (4) La evasión de cualquier tipo de sufrimiento y la resistencia para asumir compromisos de todo tipo. (5) La desacralización de la sociedad con la pérdida de los fundamentos de la verdad y del bien, que han desencadenado una erotización desenfrenada. (6) La disminución de las relaciones humanas directas trastocadas por las relaciones mediatizadas. (7) Y un complejo conjunto de problemas, como las penurias económicas, el desempleo, la hacinación en la vivienda, que privilegian el individualismo e imposibilitan para pensar en los demás y mucho menos para colaborar.

Por otro lado, la migración es un fenómeno que siempre se ha dado, las personas buscan nuevos territorios para continuar su vida de mejor modo. Sin embargo, ahora, muchas de las migraciones suceden de manera traumática. Responden a la urgencia de sobrevivir, y generalmente se apoyan en una infundada esperanza de encontrar mejores oportunidades. En estas circunstancias, los migrantes están desprotegidos y en varias ocasiones sufren el maltrato de los oportunistas. Agrava estos traslados el enfoque meramente economicista de intercambios financieros o comerciales, donde, sesgadamente, solo se busca resolver problemas laborales con menores sueldos y prestaciones. Una solución radical, no exenta de interpretaciones de privilegio para grupos políticamente bien relacionados, es la aplicación de los derechos humanos a todos, que es un proceso que requiere un noble ejercicio de la justicia propia de quien reconoce la dignidad de toda persona y de que todos somos miembros de la gran familia humana, por encima de raza, educación o creencias.

Dada la complejidad actual de la estructura social, las migraciones tienen causas imprevistas, como la de las personas que no pensaban en un traslado, pero se ven forzadas por desastres naturales o por guerras, y el Estado no tiene recursos para prestar respaldo a quienes sufren pérdidas materiales o de cualquier otro tipo. Entre las causas previstas de la migración están las de quienes sufren desempleo o buscan acceso a servicios gratuitos del sector salud, o temen cualquier tipo de persecución. Como ahora prácticamente emigran tanto mujeres como hombres, también ha aumentado la migración de niños que, cuando lo hacen solos, resulta sumamente peligrosa (Rigoni, 2013). 
Es necesario aplicar las medidas que teóricamente ya se han dado, pues los migrantes siguen desprotegidos y, por eso, expuestos a todo tipo de vejaciones:

En el contexto de crisis presente, en el que el ser humano se cotiza tan bajo, frente a la centralidad del dinero, el migrante vale todavía menos. Ni siquiera es persona pobre, sino mercancía, botín o una «minita», como externó un migrante salvadoreño. Importa mucho la ubicación social desde donde se les mire. Justamente en este contexto materialista e individualista en estado general de cuestionamiento (cultural, político, religioso, económico y social) es por donde el flujo migratorio internacional está pasando (Solalinde, 2013, p. 149).

En el fondo de todas estas cuestiones se encuentra el déficit de conciencia moral, y en este terreno la educación tiene mucho que decir y hacer. La verdadera moral refuerza la dignidad de las personas y permite cimentar los bienes. Cuando la moral está más interiorizada, mejor enfocada y comprendida, más efectivamente se aplicarán y minimizarán las pasiones negativas propias o ajenas (Manú \& Goyarrola, 2009, p. 81).

\section{Requisitos básicos para apoyar la participación}

Cualquier integración profunda requiere de un marco común solidario, con el fin de revalorar las tradiciones y fomentar el sentido de pertenencia a la propia familia, a las instituciones, a la patria. De esta manera, se cuenta con un punto de partida que contrarresta la desintegración propia del relativismo y del individualismo.

Para conseguir una solidaridad de hecho con intereses comunes, con coherencia intelectual, se podrían cuidar tres aspectos:

a) la comprensión objetiva del ser humano,

b) una fundamentación epistemológica,

c) la afinidad moral básica que fomente hechos de acuerdo con valores.

La comprensión objetiva del ser humano, a partir de una adecuada antropología, consiste en el conocimiento de su naturaleza, de sus actos y de su dignidad. Es un individuo de naturaleza racional. La persona es en sí y es con otros, tiene intimidad: intrasubjetividad, original y propia; tiene trascendencia: intersubjetividad, es capaz de establecer una red de relaciones con los demás. Todo ello lo trabaja en el tiempo de vida y forja su destino de modo original, al armonizar con sus acciones los conocimientos espontáneos, científicos, filosóficos y teológicos.

Al ser humano lo constituyen el aspecto físico (su cuerpo), la herencia (su temperamento: impulsos, instintos que subyacen), el carácter (hábitos positivos y negativos 
adquiridos que dan un sello personal), la voluntad (que se evidencia en la capacidad de elegir, amar, autodeterminarse al bien), la inteligencia (facultad espiritual, fuente de conocimientos y de saber). Estos constitutivos impregnan la estructura corpóreo espiritual, y esta unidad está llamada a alcanzar la perfección de la propia naturaleza, que consiste en alcanzar la verdad en la inteligencia y el bien en la voluntad. Este es el destino natural del ser humano que se corona con la identificación de Dios como objeto de aspiración suprema.

La filosofía no puede responder al inesperado y desconcertante hecho de que la naturaleza humana contradice su vocación y rechaza su destino, que la inteligencia cae en el error, la voluntad se aleja del bien y los instintos se rebelan. Por esto, hace falta la sabiduría superior de la teología que nos habla de la creación del ser humano como imagen y semejanza de Dios que, al desobedecer al mandato divino, pierde el estado de justicia y de santidad del que gozaba. El conocimiento teológico explica la redención ganada por Cristo, que posibilita hacerse hijo adoptivo de Dios y heredero de su gloria. Estos aspectos desentrañan la dignidad de la persona, pues está llamada a un desarrollo superior y excelente. También manifiesta su dignidad porque conoce su finalidad. Además, goza de libertad psicológica, con la cual quiere o rechaza un bien, y libertad moral para vivir o no conforme a su naturaleza. Y tiene trascendencia, porque se relaciona y deja huella (Guzmán, 1980).

Toda esta compleja y rica vida la abarca cada uno y la puede aplicar. Y gracias a la espiritualidad se es verdaderamente persona:

El ser personal o espiritual da, pues, razón de manera simultánea: 1) de la intimidad ontológica, 2) de la supremacía o elevación y 3) de la consistencia autárquica del sujeto humano; y, con todo ello, de su particular eminencia, de su dignidad [...]. En definitiva, la condición espiritual del alma humana, su trascendencia respecto a la materia, explica las dos dimensiones operativas en que se asienta la libertad de cada individuo de nuestra especie: a saber, la doble e interdependiente capacidad de conocer y querer las restantes realidades y, de manera muy particular, a las personas, tal y como son, sin someterlas a las falsificaciones derivadas de los propios intereses (Melendo \& Millán, 1996, p. 114).

La fundamentación epistemológica consiste en el fomento de la racionalidad objetiva que la realidad ofrece a toda inteligencia. La adquisición de la verdad es una posibilidad humana y se actualiza con el estudio ponderado y libre de prejuicios, que de modo natural llevan al conocimiento de las cosas en sí o por sus causas.

El conocimiento empírico de las ciencias sociales, con toda su importancia, no trasciende la apariencia objetiva y fenoménica. Es conocimiento de la realidad espacio-temporal que, por su propia naturaleza, está sometida a los cambios incesantes de la historia y de las contingencias del medio físico-geográfico. 
El conocimiento metafísico llega a la realidad profunda, entrañable, íntima. Es el conocimiento de la esencia del ser de las cosas y de la realidad social. Ya no es observable, pero sí inteligible. Es el conocimiento de los datos últimos de los cuales podemos saber el origen-causa eficiente, la finalidad-causa final, los elementos constitutivos-causa material y aquello que le hace ser ella y no otra realidad distinta-causa formal (Guzmán, 1980). Con estos datos se facilita reconocer lo que no puede cambiar de lo que sí, lo inalterable y definitivo de lo adaptable a las circunstancias. Y el ser humano ha de armonizar los conocimientos palpables, científicos y teológicos.

La afinidad moral básica, que fomente hechos de acuerdo con valores, se debe a la ubicación de la persona como criatura, que recibe del Creador unos principios insoslayables y buenos para todos. Esta convicción elimina la veleidad de fincar el bien en criterios humanos que están muchas veces sujetos a opiniones poco profundas o a modificaciones por intereses de conveniencia.

La quiebra moral de la civilización tiene varias causas, citamos algunas: el humanismo de inmanencia y el antropocentrismo que fomenta el aislamiento individualista; la liberación de principio, preceptos y normas que se cierran a la evidencia de lo real; la independencia de lo que se considera una restricción que lleva a estar fuera de la ley; la autonomía para regirse por sí mismo, en el terreno intelectual provoca el rechazo de la teología, en el campo moral, el desconocimiento de la voluntad de Dios, en la antropología, la alteración de la naturaleza humana, en lo social, la sustitución de los fundamentos éticos y jurídicos, en lo político, el divorcio de la moral, en la educación se sustituye el perfeccionamiento por el adiestramiento, la capacitación técnica y la instrucción profesional; en el orden económico, se desdeña la jerarquía y este orden se coloca en un primer nivel.

Con todo esto vemos que a la persona se la degrada con doctrinas positivistas que niegan la metafísica, con neopositivismos, con biologismos que niegan el espíritu, con psicologismos y sociologismos que solamente admiten las ciencias naturales. Otras veces exaltan a la persona deificándola, como sucede con los inmanentismos racionalistas y voluntaristas. Ciertas posturas abandonan a la persona, pues la convierten en un recurso, es el caso del economicismo; se provoca entonces la masificación, la despersonalización, una existencia vana (Guzmán Valdivia, 1980).

Para el logro de la racionalidad objetiva, la sociedad civil ha de sanear el ambiente, evitando presiones ideológicas y totalitarias que confunden las mentes. Para fomentar la moral básica que se manifieste en actos buenos se ha de erradicar la pornografía, la permisividad erótica, la corrupción, la injusticia como táctica; en definitiva, todo aquello que deteriora a la naturaleza humana o que atrofia su desarrollo. 
Como el núcleo familiar es el ámbito propio para el crecimiento humano, las ayudas públicas han de abordar múltiples factores, como la vivienda adecuada, los apoyos en el terreno educativo, los horarios laborales que permitan la convivencia en el hogar, la revalorización del oficio de ama de casa.

En general, en todas las instituciones se ha acentuado la crisis de autoridad y la crisis de convicciones. La solución está en fortalecer el comportamiento de quienes tienen una función directiva o desempeñan tareas en niveles superiores, para que sirvan de ejemplo y para que, cuando tengan que dilucidar los asuntos de su competencia, juzguen y decidan con rectitud.

La participación será una realidad si se neutralizan las fuerzas negativas, prevalece lo común y hay grupos institucionales, naturales, formales, informales, etc., a los que todos tengan acceso, pues el trabajo comunitario es trabajo con grupos que están unidos por objetivos comunes. Cada grupo ha de ser una unidad de trabajo con tareas concretas, pero abierto a la acción participativa. Para ello, hace falta un plan apoyado en un marco teórico referencial y en una investigación diagnóstica, que coordine y programe las distintas actividades con el fin de lograr las metas propuestas. Así será posible vertebrar a todos los grupos, con la ayuda de los líderes sociales, y producir un movimiento coordinado y total, porque las comunidades pueden desarrollar su capacidad para resolver sus problemas (Kisnerman, 1984, p. 75).

\section{Medios educativos en la familia}

La característica de la educación familiar consiste en incidir en la totalidad de la persona, en ese ámbito se logra, de manera natural, la integración de las diversas facetas de otros estímulos educativos que vienen de fuera. Además, es posible alcanzar la armonía de la personalidad porque con facilidad se detectan las cualidades y se fomentan, y al detectar los defectos se busca eliminarlos. Entonces cabe decir que la educación familiar consigue buenas personas.

Además, la fluidez natural de la vida muestra la primacía social de la familia, que es el primer pilar social, de manera que sin familia no hay sociedad, y esta es una visión radicalmente opuesta a doctrinas liberales o socialistas (Alvira, 1980).

Conseguir buenas personas es tarea del día a día, con un mosaico riquísimo de circunstancias, por eso, abordar positivamente las tensiones naturales entre padres e hijos y resolverlas de la mejor manera resulta una especie de microuniverso que capacita para afrontar y solucionar problemas más difíciles en el campo social y laboral. 
Hacen falta mujeres y hombres capaces de expresar su postura ante la banalización del adulterio (causa o efecto del divorcio), ante el olvido de la castidad, ante el menosprecio de los ancianos, ante la relativización de los valores religiosos, y otros asuntos.

Al fundamentar estas metas es importante el papel que la familia tiene en la educación para el amor. Allí se aprende que el amor tendencia se hace amor humano por el acto de la voluntad que elige a una persona para ser depositaria estable de amor. Por lo tanto, se concreta la tendencia natural, eligiendo después de seleccionar. Y la elección sostenida no es otra cosa que el ejercicio recto de la libertad. Por eso, para madurar en el amor, primero aparece el amor tendencia, en donde se aprecia lo que es bueno "para mí», pero luego se debe pasar al amor benevolente, que busca lo bueno «para ti».

Si los cónyuges realizan este proceso, su vida será ejemplo para los hijos. Ellos, al captar esta realidad, podrán imitarlos y prestar ayuda, en la medida de su edad y posibilidades, a sus compañeros en la escuela, a los vecinos, especialmente a los enfermos y ancianos, más adelante, a los compañeros de trabajo y, como una señal de madurez, en la elección del compañero de su vida.

El proceso del paso de la inestabilidad a la estabilidad en los hijos se hace posible gracias a la estabilidad que estos vean en la relación entre su padre y su madre. De manera natural, los hijos captan el trabajo como servicio cuando ven esos detalles en la mamá y en el papá. Aprenden a administrar la libertad con la fuerza del ejemplo de los padres cuando descubren actitudes adecuadas en los mayores. Pero también la falta de dominio de los progenitores es un estímulo negativo para la prole.

La tarea educativa de los padres ha de proceder de la confianza en que los resultados se darán y en el hecho de que al ámbito familiar le corresponde, primariamente, reivindicar la disciplina y espiritualizar la sexualidad. Así se forja el talante recio de las personalidades y el profundo sentido de respeto a los demás.

La educación para la participación empieza con la asignación de encargos. La distribución de tareas aporta el beneficio del sentido de pertenencia, por el hecho de tener un quehacer; del sentido de responsabilidad, cuando aprecian los beneficios de cumplir; del trabajo en equipo, porque todos los miembros de la familia aportan con lo que les corresponde.

La educación en la fe es el culmen de la educación, pues, en este proceso, los padres dan a sus hijos lo más rico que poseen. La relación con Dios corona la formación, allí se descubre el sentido último de los actos. La fe se deposita en la inteligencia, 
pero, si se hace vida, da una manera de estar muy superior a la de cualquier otra conducta. La educación en la fe dentro de la familia se realiza no en un momento o con unos medios determinados, sino como algo integrado, provoca un modo de ver, de sentir, de apreciar, de entender y de querer totalmente congruente.

En el hogar, la solidaridad intergeneracional se logra de una manera natural, consiste en el cuidado de los ancianos y de los niños. También en el seno familiar es más fácil fortalecer la identidad personal y social para forjar ciudadanos seguros y solidarios.

Cada uno de estos aspectos se alcanza con el seguimiento de las personas hasta lograr que realcen las actividades propuestas de manera fácil y grata, porque están convencidos de que ha valido la pena el esfuerzo, así en sucesivas ocasiones serán capaces de volverlo a hacer. En esto consiste la virtud: en realizar actos buenos con agrado y facilidad. La adquisición de virtudes es la meta de la educación, porque, con ellas, cada uno coopera fortaleciendo la naturaleza propia (López de Llergo, 2003). Pero es imprescindible el ejercicio más noble de la libertad, sin el cual no es posible alcanzar las virtudes:

Los hombres necesitan las virtudes del mismo modo que las abejas sus aguijones. Una abeja puede perecer al clavar el aguijón, pero las abejas siguen necesitando igual sus aguijones; un hombre individual puede perecer por ser valeroso o justo, pero los hombres siguen necesitando igual la fortaleza y la justicia. Es igualmente sofístico escribir como si la alternativa fuera: o virtud moral por sí misma o egoísmo. Los hombres están hechos de tal modo que se preocupan por lo que les pasa a los demás (Geach, 1993, pp. 53-54).

\section{Medios educativos en el sistema escolarizado}

En primer lugar, la institución educativa subsidia a la familia en todos aquellos aspectos cuyos medios no se tienen en la casa. Directamente le corresponde formar personas capaces de desempeñarse en la sociedad a través de los servicios profesionales. También capacita para aprender a relacionarse con personas de diversos estratos, con variados enfoques, etc. En definitiva, prepara para ubicarse en un ambiente plural, y con aportaciones pertinentes que ofrezcan beneficios y enriquezcan el bien común.

En la actualidad hay una proporción más elevada de planteles educativos y, además, la tecnología hace posible llevar a regiones con menos recursos los medios con que no se contaba. Esto hace posible superar algunos problemas antes impensables.

Sin embargo, los contenidos de los medios, entre otros estímulos, agravan las rebeldías estudiantiles porque siguen ejemplos que no estaban a su alcance en otros 
tiempos. La promoción de la delincuencia, la inseguridad, la miseria y la violencia no encuentran antídoto en una educación moral y religiosa insuficiente o nula. Muchas veces se presentan una serie de normas inconexas que no se aceptan porque no se advierte el sentido que tienen.

El reto para los docentes consiste en la necesidad de elevar su preparación y de llegar a la raíz de los problemas vitales para presentar vías de solución. Se trata de erradicar el miedo a la vida, la agresividad incontrolada, la ignorancia, la desorientación, la incompetencia profesional, la ceguera ante el sentido de la vida, la falta de amor, el miedo a enfrentarse consigo, el temor a establecer relaciones duraderas, la incapacidad para establecer lazos sociales permanentes.

Comentando las enseñanzas de Monseñor Escrivá de Balaguer respecto de la educación y el quehacer educativo, Francisco Ponz, entonces Rector de la Universidad de Navarra, escribía las siguientes palabras: «Libertad y responsabilidad, libertad y autoridad, confianza y desvelo, cariño y fortaleza, amistad y respeto: pares de elementos que han de conjugarse adecuadamente en cualquier acción educativa, que deben complementarse mutuamente para que la personalidad pueda desarrollarse con la mayor plenitud» (citado por García Hoz, 1980, p. 734).

La institución educativa presta un servicio subsidiario a la enseñanza no sistemática recibida desde la familia. También en el tema de la fe, pues, especialmente, cuando se llega a la adolescencia, hace falta contar con la colaboración de la escuela, integrando los conocimientos del plan de estudios, de manera que vean de modo natural y práctico las relaciones de fe y razón, de fe y ciencia.

Propiciar actividades donde se identifiquen y forme a los líderes, y conocer su radio de influencia para darles seguimiento, hasta ponerlos en condiciones de actuar por sí mismos. Organizar campañas de sensibilización hasta captar la importancia de las acciones ecológicas y promover aquellas que benefician a todos en el presente y el futuro. En un plan ecológico educativo se ha de llegar a entender la razón del uso racional de los recursos para que, en su momento, los educandos sepan cuidarlos y aprovecharlos debidamente.

Para fortalecer el ejercicio de la libertad, habrá que eliminar cualquier forma de autoritarismo, paternalismo o manipulación. Y como la institución educativa es experta en la mejora del ser humano, consigue querer tender a la plenitud. En palabras de Altarejos (1986): «Podría decirse que la actividad feliz es la actividad superior del hombre, en el sentido de la más conveniente, la más adecuada; y, por ello, la más plena, la que da cumplimiento a la existencia» (pp. 128-129). 
Entre los medios, el calendario escolar puede ser un buen recurso ordinario para aprovechar las fechas que conmemoran símbolos, tradiciones, folklore, efemérides, etc.; y así fomentar el sentido de pertenencia a esas tradiciones, que ofrecen lazos de unión entre los ciudadanos.

Es aconsejable descubrir conductas antisociales, como son los resentimientos, las envidias, la discriminación, el desprecio; y aplicar técnicas individuales o grupales para eliminar esas tendencias que más adelante pueden promover la corrupción, la injusticia o la criminalidad. En ese sentido, es necesario llegar a tiempo, especialmente con la niñez, que está inerme ante el embate de tantos estímulos, inerme porque aún no tiene criterio:

Mucho también del contenido de la conciencia viene determinado por el colectivo moral. Lo que el niño encuentra establecido como válido por la comunidad en el ámbito de la moralidad, de las costumbres, de la corrección, de los usos y del derecho, no puede menos de dejar su huella en el desarrollo ulterior de la persona. [...]. A causa de semejantes hechos, somos propensos a perder la confianza en el dictamen de la conciencia. Mas esto no es correcto, pues, al margen de todas las limitaciones y provisionalidad en el contenido moral de la conciencia, permanece siempre un resto que, al menos como posibilidad, no parece ser exclusivamente de tipo formal, y que puede muy bien ser reconocido como regulador interno de la acción humana (Dürr, 1971, pp. 86-88).

Como la conciencia mantiene un diálogo con las experiencias, es moldeable, flexible y por eso se puede educar. Así, en la educación superior, la meta ha de enfocarse en lograr la serenidad interior y la ponderación para valorar los frutos del estudio, se trata de alcanzar la verdad y gozarla promoviendo la paz interna y externa:

[...] el vacío existencial significa la carencia de cuanto el hombre necesita para desarrollarse cabalmente como persona. Lo que necesita es, en definitiva, vínculos auténticos, modos elevados de unidad, es decir, encuentros. Los encuentros no se dan por la vía del vértigo, sino de su polo opuesto: el éxtasis. [...]. Este gozo se transforma en entusiasmo cuando me encuentro con realidades muy valiosas que me ofrecen posibilidades suficientes para elevarme a lo mejor de mí mismo. Esta elevación me saca de un estado inferior de realización para auparme a otro superior. Podemos decir que me saca de mí. Por eso le llamamos «éxtasis» [...]. Pero no me saca de mí para perderme, como sucede con el vértigo, me saca para llevarme a la plenitud (López Quintás, 1993, pp. 62-63).

\section{Medios educativos en la sociedad}

En el terreno educativo, de la sociedad se espera la capacidad de lograr un entorno con variadas posibilidades para que los ciudadanos puedan encontrar dónde ofre- 
cer sus servicios, esto es, promover fuentes de trabajo. También se espera la protección del seguro desenvolvimiento de las personas y la promoción de los valores de la solidaridad, la subsidiariedad, el respeto y la lealtad, emulando o sancionando, según sea la conducta de las personas. Estos cuatro valores sociales y relacionales impulsan la participación, nunca excluyente, en una causa o empresa común y son motivo de relaciones humanas venturosas. Tales relaciones dan cohesión interpersonal, al fomentar intereses grupales y generar obligaciones asumidas con responsabilidad por el ejemplo recíproco (López de Llergo, 2003, p. 79). Un pueblo educado es un pueblo que, aunque, como es probable, no cuenta con todos los satisfactores, sabe buscarlos, pone los medios y evita la violencia destructiva. Con la educación se consiguen comunidades felices porque tienen esperanza y concretan el camino a seguir.

La promoción del ejercicio de la libertad es condición para el bienestar de los ciudadanos, pero, con frecuencia, aparece la tendencia a reprimir para que todo marche bien; sin embargo, esa paz es ficticia, pues falta la verdadera aportación de los miembros de la sociedad:

\begin{abstract}
Toda conducta genuinamente inteligente se decanta en lo que podríamos llamar líneas maestras de conducta. Pero la condición previa de la libertad es necesaria. A lo largo de la historia, aparecen cuatro situaciones claras de falta de libertad. El salvaje primitivo no es libre: acuciado día a día por las necesidades básicas, es como un vehículo que debe emplear su escaso combustible en conseguir más combustible. El esclavo dispone de combustible, pero tiene la dirección bloqueada, tampoco es libre. En la actualidad los pueblos sumidos en la miseria del tercer mundo carecen de la libertad real, como los primitivos. Y los que viven bajo un régimen totalitario tienen bloqueada la dirección, como una versión moderna de la vieja esclavitud (Ayllón, 2005, p. 30).
\end{abstract}

La generalizada solución democrática para intervenir en los problemas sociales requiere de un alto nivel de educación para poder participar y defender lo imprescindible: en este caso hablamos de la libertad. En la sociedad civil es difícil tener una relación basada en el conocimiento de los demás, para mostrar un aprecio individualizado, sobre todo en los grandes conglomerados de las capitales contemporáneas. Sin embargo, careciendo de esa cercanía, sí se espera una convivencia respetuosa que procure el bien de todos, y que podría denominarse «amistad política», porque a todos nos importa la buena disposición del territorio que nos acoge y la mejor conducta de los ciudadanos. Por lo tanto, la relación política se ha de basar en una comunicación humana donde se distinga lo justo de lo injusto, lo bueno de lo malo, donde sepamos defender los elementales derechos humanos, y evitar los privilegios para unos pocos. 
La integración de los medios de comunicación social está llamada a ser una ayuda importante, por eso, la autoridad civil ha de poner los medios para cuidar la información veraz y la difusión de valores morales, evitando la promoción de escándalos o de otras formas de corrupción que puedan ocasionar curiosidad y, más adelante, ser ejemplo nefasto, especialmente, para los jóvenes.

Una manera de organizar y facilitar la participación puede llevarse a cabo planteando tres niveles de ciudadanos activos: voluntarios, técnicos y expertos. Los principales criterios de selección de voluntarios son la experiencia y competencia profesional, las cualidades humanas, el respeto a los demás y la capacidad de convivir con otros. Así, la comunidad será enriquecedora por las oportunidades que ofrece, y será tangible y real la posibilidad de acceder a mejores condiciones de vida.

\section{Conclusiones}

Es necesario, para entablar relaciones, entender la mentalidad del interlocutor para encontrar el lenguaje y las motivaciones profundas que puedan reconducirle a ideales nobles y elevados, aunque se muevan en ambientes permisivos y decadentes. El ejemplo y las convicciones son estímulos contundentes.

Una vez establecida la relación, será más fácil impulsar a ser agentes activos y responsables del propio progreso, usando medios, como la investigación en común de los problemas locales, el planeamiento y la ejecución por sí mismos de las soluciones que antes convinieron, y la coordinación voluntaria con los demás grupos y con las autoridades oficiales, de modo que se obtenga el bienestar.

La familia es por naturaleza formadora de personas y foco de irradiación en la sociedad. Por estos motivos es necesario salvaguardar su función sin ignorar las aportaciones de otras instituciones, aunque siempre buscando la integración de fines y de principios.

Lo importante es que la responsabilidad personal se haga responsabilidad social y se exprese tangiblemente en la calidad de vida. Así, la participación se llevará a cabo en un clima de respeto a los valores y a las tradiciones del contexto cultural de cada nación, y sin violentar su legítima soberanía.

Dos elementos son esenciales en la participación solidaria y comprometida: la inclusión de la población y la intervención de instituciones gubernamentales, no gubernamentales y voluntarias, para suministrar ayudas de todo tipo que aumenten la eficacia y capitalicen el esfuerzo y el trabajo de los integrantes de la comunidad. Sin embargo, es importante evitar dos suposiciones erróneas: que las comunidades 
son realidades homogéneas con intereses compartidos por todos sus miembros y que las personas quieren participar y ponen los medios.

Para terminar, se presenta un elenco de actividades que pueden servir de guía:

- Postular una cultura de solidaridad, de subsidiariedad, de respeto y de lealtad, por medio del cultivo de las virtudes.

- Actuar en un plano democrático, tanto en la formulación de objetivos como en la distribución de las responsabilidades directivas o colaborativas a distintos niveles.

- Fomentar la actitud de gratuidad a través del voluntariado y de las actividades no lucrativas.

- Promover la capacidad de proyectarse para conseguir un fin asumido como válido y mejorar a la comunidad, mediante la acción directa, el control y la evaluación.

- Contrarrestar la politización, corrupción y apatía.

- Favorecer la obtención de recursos y, cuando se tienen, hacer uso de ellos con sentido de responsabilidad para beneficio de todos.

- Facilitar la participación de los demás impulsándolos a dar lo que deben.

De manera sintética, el siguiente párrafo expresa la esencia radical de la participación generosa y comprometida:

Darse cuenta de que somos nosotros mismos - unos con otros- quienes nos encontramos en el origen mismo de las transformaciones sociales. Es entonces cuando cada acto de libertad abre nuestros espacios para el ejercicio de la propia libertad. La libertad vuelve sobre sí misma y se auto potencia. Y el bien moral está en la línea de ese crecimiento en excelencias operativas o, si es preferible, en virtudes éticas cuya raíz y culminación es la capacidad de amar (Llano, 2002, p. 195).

\section{Referencias}

Altarejos, F. (1986). Educación y felicidad (2. a. ed.). Pamplona: EUNSA.

Alvira, R. (1980). ¿Persona o individuo? Consideraciones sobre la radicalidad social del hombre. En Sarmiento, A. (Coord.). Cuestiones fundamentales sobre matrimonio y familia (pp. 459-464). Pamplona: Universidad de Navarra.

Aquino, T. de (1954). Suma Teológica. Madrid: Biblioteca de Autores Cristianos.

Ayllón, J. R. (2005). Desfile de modelos. Análisis de la conducta ética (6. ed.). Madrid: Rialp.

Dürr, O. (1971). La educación en la libertad. Madrid: Rialp. 
García Hoz, V. (1980). La familia y la tarea educativa. Una pedagogía del amor. En Sarmiento, A. (Coord.). Cuestiones fundamentales sobre matrimonio y familia (pp. 715-746). Pamplona: Universidad de Navarra.

Geach, P. T. (1993). Las virtudes. Pamplona: EUNSA.

González Simancas, J. L. (1992). Educación, libertad y compromiso. Pamplona: EUNSA.

Guzmán Valdivia, I. (1980). Doctrinas y problemas sociales. México: Editorial Jus.

Kisnerman, N. (1984). La comunidad. Buenos Aires: Editorial Hvmanitas.

Llano, A. (2002). La vida lograda. Barcelona: Ariel.

López de Llergo, A. T. (2003). Educación en valores, educación en virtudes (6. ${ }^{\text {a. }}$ impr.). México: CECSA, Patria Cultural.

López Quintás, A. (1993). La cultura y el sentido de la vida. Madrid: PPC, SA.

Manú, J. M., \& Goyarrola, I. (2009). Educar. Los retos del siglo XXI. Madrid: Rialp.

McLuhan, M., \& Powers, B. R. (2007). La aldea global. España: Gedisa.

Melendo, T., \& Millán, L. (1996). Dignidad: ¿Una palabra vacía? Pamplona: EUNSA. Messner, J. (1976). La cuestión social. Madrid: Rialp.

Rigoni, F. M. (2013). El cambio de rol de la mujer centroamericana en el contexto de la globalización. En Plascencia, R. (Coord.). México, movilidad y migración (pp. 161-176). México: Comisión Nacional de Derechos Humanos.

Solalinde, A. (2013). La migración desde la perspectiva de personas defensoras de los derechos humanos de las y los migrantes. En Plascencia, R. (Coord.). México, movilidad y migración (pp. 149-16o). México: Comisión Nacional de Derechos Humanos.

Utz, A. F. (1965). Ética Social II. Barcelona: Herder. 